\title{
Single-Well Modeling Study In Buzurkan Oil Field
}

\author{
Mazin H. Al-Attar* And Mohammed S. Al-Jawad** \\ *Senioryear Student,Department Of Petroleum Engineering / University Of Baghdad \\ ***Professor Department Of Petroleum Engineering / University Of Baghdad
}

\section{$\underline{\text { Abstract }}$}

$$
\text { Single well modeling }
$$

technique is considered as an important tool in simulation studies that deal with the near well issues (i.e. water coning, optimum perforation intervals, etc.); or it may be used in the determination of the final acceptability of the entire field model (1). In this study, this technique is adopted to study and characterize one of the producing wells in Buzurkan oil field which is BU-3. The probability of the increase of water production will be tested with different production schemes, because if the well has to produce with certain water rate, the surface facilities have to be designed to be suitable for that rate. Water saturation distribution around the well is also inspected through the history of the well to determine the reason behind water production.

CMG simulator has been used to perform this study. The results matching are based on the pressure and the produced water cut history and show good match in both cases.

The model showed that there is a significant increase in water production with increase of oil rate due to water coning.

\section{Introduction}

$$
\text { Simulation of petroleum }
$$

reservoir performance refers to the construction of a model whose

behavior assumes the appearance of actual reservoir performance. Numerical solution of the partial differential equations that is 
necessary to set up a mathematical model is become increasingly feasible with the advent of modern computers. Radial simulators, sometimes known as coning models are one-well models that are used primarily to study well tests, coning phenomena, induced fracture effects, well completions and other individual well factors. This type of models must be fully implicit to account for rapid saturation changes that will occur around the wellbore (2)

Coning is a phenomenon where water is drawn up into the wellbore due to the production rate. Since water is denser than oil, there are gravity forces opposing the growth of the water cone. For a given oil production rate there is a particular height above the water-oil boundary at which the cone's apex will come to rest in equilibrium. In such case,

there exist a critical production rate above which no stable cone can be formed. The aim of this study is to characterize and build a model for
BU-3 in order to check future water production probabilities ${ }^{(2)}$.

\section{Brief Description Of}

\section{Buzurkan Oil Field}

Buzurkan oil field lies in the southern of Iraq, north east of Omara city near the Iraqi-Iranian borders. This field consists of two domes, south and north dome. The first well drilled in the north dome in 1969. The field is producing from Mishrif formation which consists of several units. The most important units among them are MB21, MC1 and MC2. The well which is considered in this study is BU-3. It lies in the southern dome. This well starts production in 1978 from MB21 unit and still active until now. The well has two perforated intervals both in MB21

unit. This well has many points of pressure measurements unlike many other wells, and this one of the reasons behind selecting this 
well for the study. Also it has both $\log$ and core data that help in the vertical gridding process. Another reason for selecting this well is the high produced water cut compared to other wells which will be a matter of discussion in this study. Also for simplicity sake, as this well perforated only in MB21unit so this could be considered as another motivation to select this well ${ }^{(3)}$.

\section{Model Characterization}

\subsection{Grid Construction}

Radial model has been adopted in his study. The borehole radius was considered as $0.15 \mathrm{~m}$, and then the drainage radius was approximated by taking the midpoint distance between $\mathrm{Bu}-3$ and the adjacent wells. The model was divided into 10 grids in $r$ direction with $\Theta=360$.

\subsection{Qualitative Vertical Gridding \\ The second step was to}

divide the layers in the $\mathrm{z}$-direction. MB21 unit is the only reservoir unit from which the well is producing. This unit should be finer subdivided in order to get the most accurate properties for each layer as the model considers homogenous properties for each one. This process is done by comparing the data from $\log$ and core porosity with the values of permeability and water saturation and taking the perforation intervals in consideration. Accordingly, the unit is divided into 12 layers. The first two layers contain the first perforation interval while the second interval is in the eighth layer and the last four layers are sinking in water. This process is important as this study is interested in the vertical movement of fluids around the wellbore. Fig. (1) illustrates the vertical gridding process. 


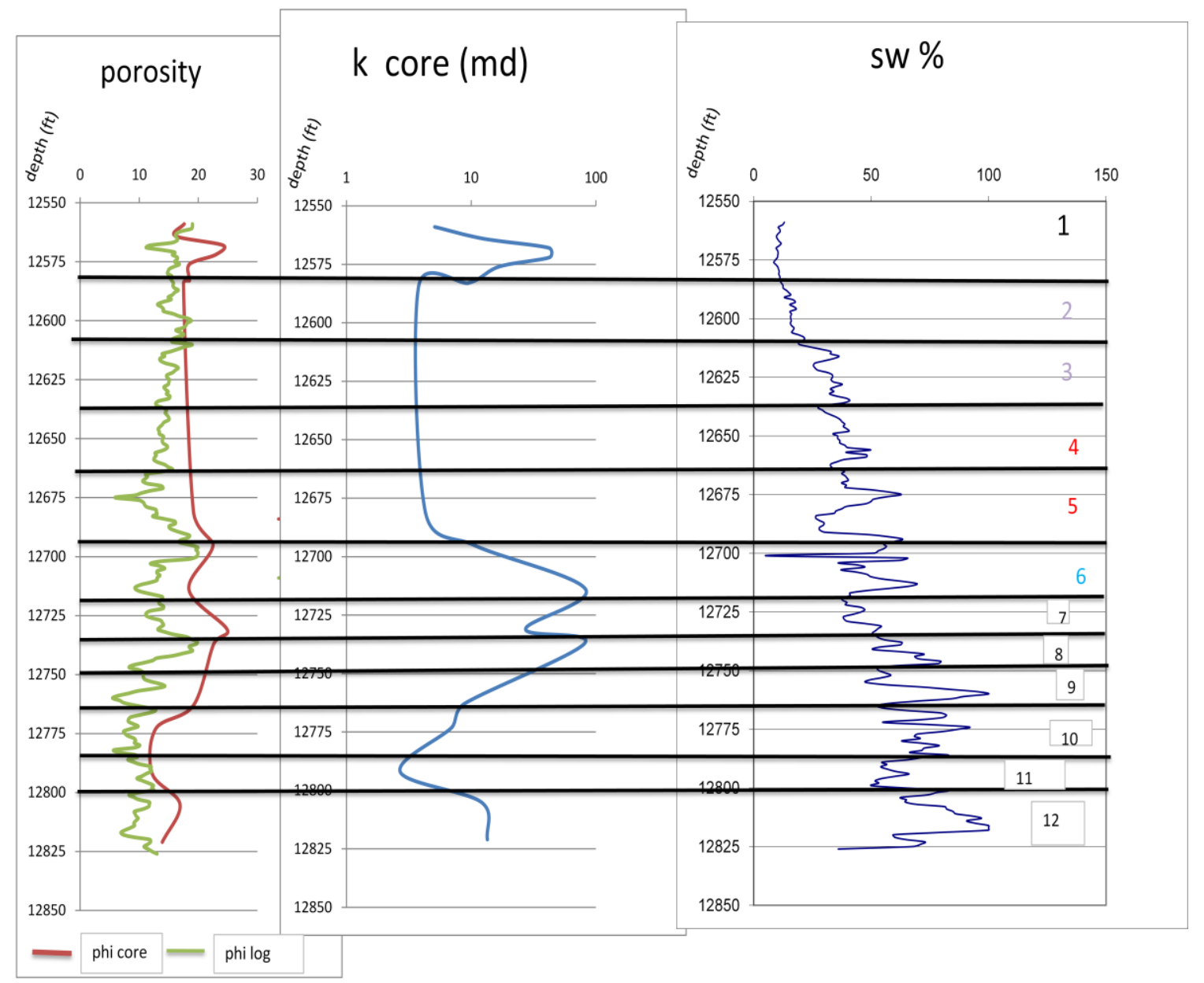

Fig. (1) The Change of Porosity Permeability and Water Saturation with Depth

\section{3. $\quad$ Rock Properties}

Rock properties assigned for each grid and they are obtained from log and core data ${ }^{(4,5)}$. These properties are illustrated in table 1 for each layer. 
Table (1) Reservoir Rock Properties for Each Layer in MB21 Unit

\begin{tabular}{|c|c|c|c|c|c|c|c|c|c|c|}
\hline & Top, m & & $\begin{array}{l}\text { Bottom, } \\
\mathrm{m}\end{array}$ & $\begin{array}{l}\text { Gross } \\
\text { Thickness, } \\
\text { m }\end{array}$ & $\Phi \%$ & Sw\% & $\begin{array}{l}\text { Net } \\
\text { Thickness, } \\
\text { m }\end{array}$ & Notes & $\begin{array}{l}\mathrm{K}_{\mathrm{H}}, \\
\mathrm{md}\end{array}$ & $\begin{array}{l}\mathrm{K}_{\mathrm{v}}, \\
\mathrm{md}\end{array}$ \\
\hline 1 & 3826.459 & - & 3834.384 & 7.9248 & 15.12 & 12.3 & 7.5 & Perf & 23.8 & 23.733 \\
\hline 2 & 3834.384 & - & 3843.528 & 9.144 & 15.9 & 15.3 & 9 & Perf & 30 & 6.65 \\
\hline 3 & 3843.528 & - & 3851.148 & 7.62 & 15.14 & 30.9 & 7.5 & & 25 & 6.5 \\
\hline 4 & 3851.148 & - & 3860.292 & 9.144 & 13.9 & 37.1 & 9 & & 25 & 6 \\
\hline 5 & 3860.292 & - & 3867.912 & 7.62 & 12.29 & 40.1 & 7.2 & & 20 & 4.3 \\
\hline 6 & 3867.912 & - & 3875.532 & 7.62 & 15.33 & 50.1 & 5.4 & & 82.6 & 10.5 \\
\hline 7 & 3875.532 & - & 3878.885 & 3.3528 & 12.69 & 43.6 & 3.3 & & 20 & 15 \\
\hline 8 & 3878.885 & - & 3883.152 & 4.2672 & 16.01 & 50.2 & 3.6 & $\begin{array}{c}\text { perf } \\
\text { (pluged) }\end{array}$ & 50 & 54.3 \\
\hline 9 & 3883.152 & - & 3887.724 & 4.572 & 12.27 & 61.4 & 2.7 & $\mathrm{Wtr}$ & 28 & 10 \\
\hline 10 & 3887.724 & - & 3896.868 & 9.144 & 9.006 & 73.3 & 1.8 & Wtr & 15 & 7.9 \\
\hline 11 & 3896.868 & - & 3901.44 & 4.572 & 11.09 & 58.7 & 2.4 & Wtr & 13 & 2.7 \\
\hline 12 & 3901.44 & - & 3909.365 & 7.9248 & 10.02 & 77.6 & 0.3 & Wtr & 12.1 & 5.5 \\
\hline
\end{tabular}

\subsection{Reservoir Fluid Properties}

B lack oil fluid model was chosen to simulate the reservoir fluids. This model was chosen to take into consideration any possibility of gas libration in the future. As the PVT data for BU-3 is not available, the PVT data for BU5 was taken ${ }^{(6)}$ because this well lies on the same contour line of the formation's top map and have the same perforation interval depth. Only one PVT region is considered because it was found that there is no change in the PVT properties along the different layers.

This conclusion is made after the revision of the PVT properties that obtained from other wells from different sampling depths which found to be identical ${ }^{(3)}$. PVT curves are shown in figures 2 to 4 . 


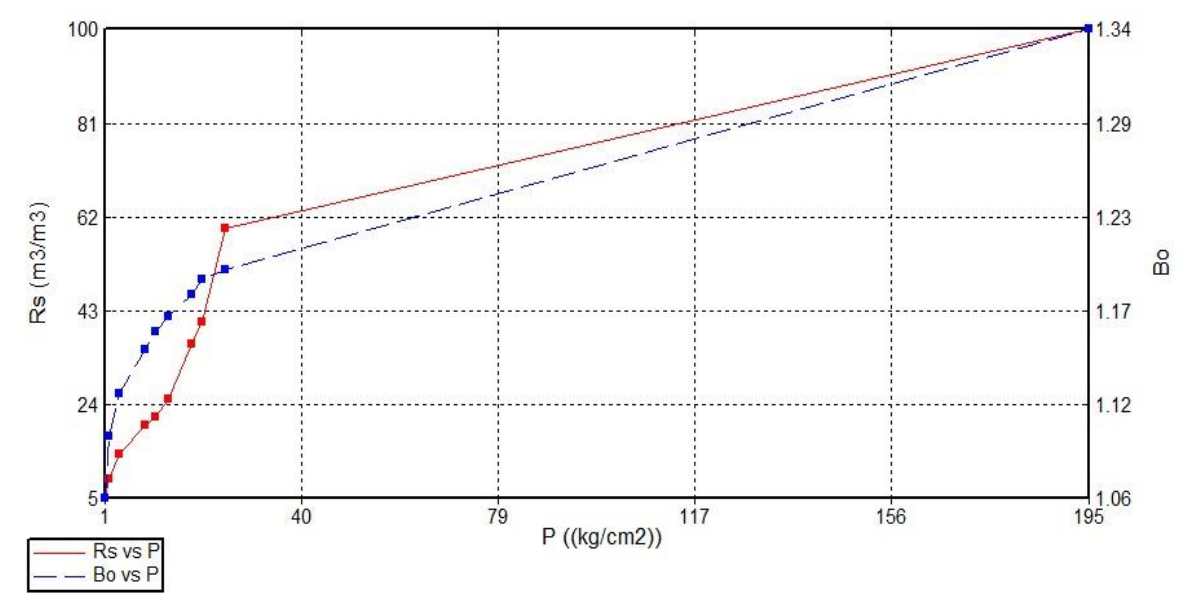

Fig.(2) Oil Formation Volume Factor and Dissolved Gas Oil Ratio versus Pressure

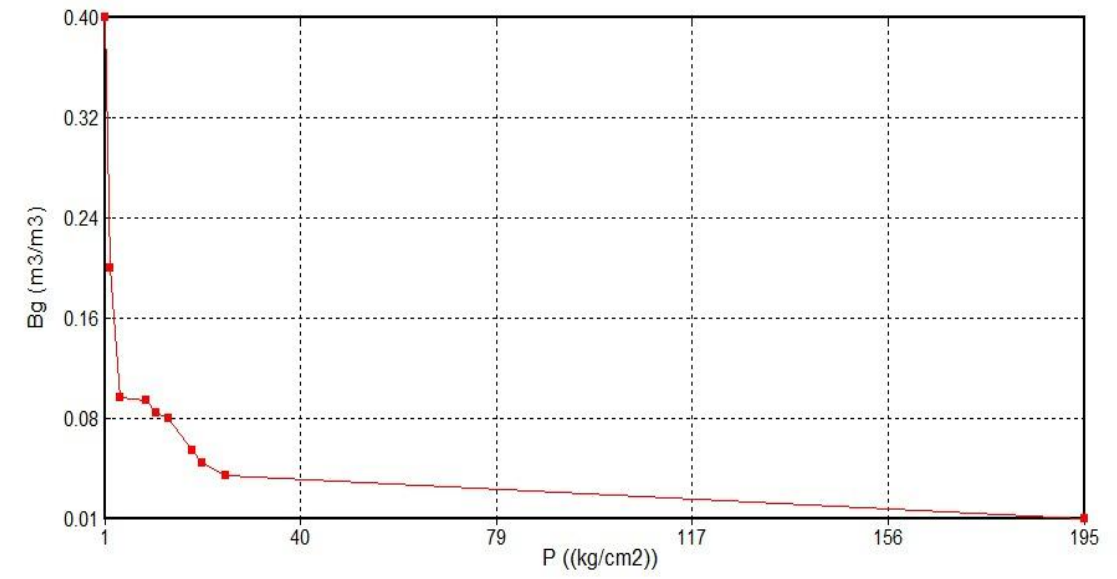

Fig. (3) Gas Formation Volume Factor versus Pressure

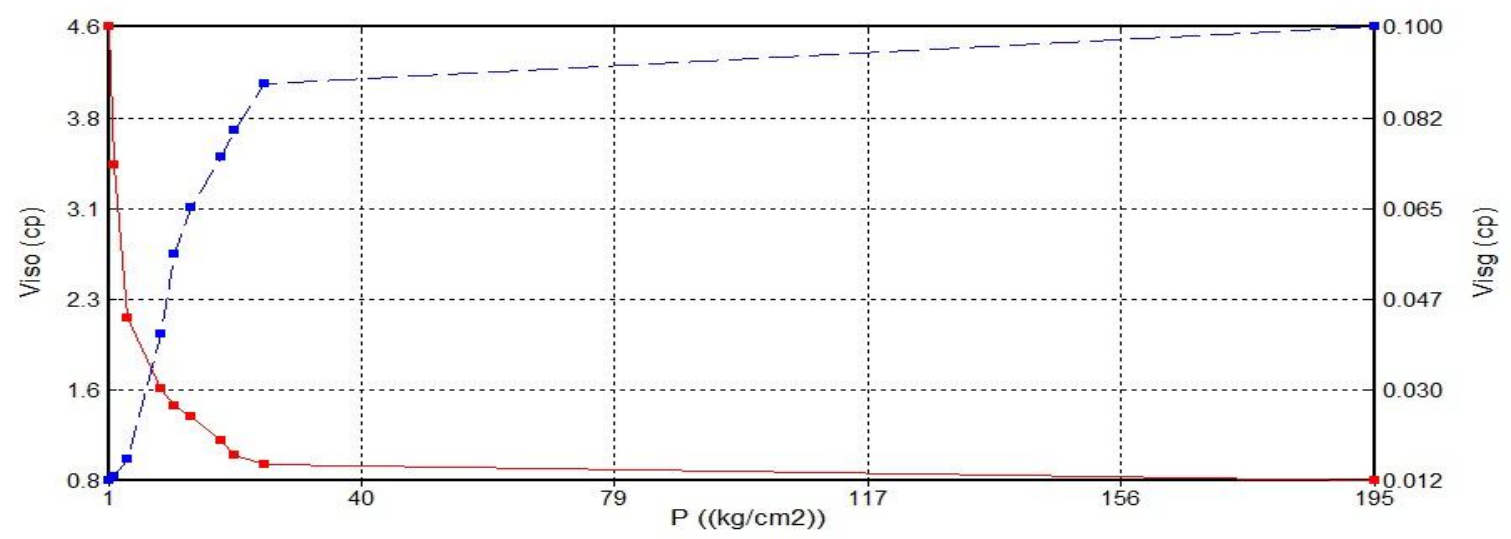

Fig .(4) Oil and Gas Viscosities versus Depth 


\subsection{Initial Conditions}

From $\log$ analysis, the

oil- water contact is found to be at $3330 \mathrm{~m}$. and for the initial reservoir pressure there is a unique measured value of $438 \mathrm{Kg} / \mathrm{cm}^{2}$ (6216 psi).

\subsection{Boundary Conditions}

A flow boundary (with an aquifer) has been encountered as a boundary condition in the current study. The type of aquifer is considered as bottom water drive aquifer. The water influx at the flow boundary was simulated by Fetkovitch method. This method was found to be best validated through the history matching process for the reservoir under study.

\subsection{Production Schedule}

The simulation time for the current study is thirty years that is from 1977 to 2007. This includes a nonproductive period extending from 1980 to 1999. The maximum oil rate that reached during the well life is $435 \mathrm{~m}^{3} /$ day ${ }^{(7)}$.

\section{Results And Discussion}

The results of $\mathrm{Bu}-3$ in

Buzurkan oil field are obtained by using CMG simulator and it will be presented and discussed in the following sections. 


\subsection{Results Of History Matching}

Many runs have been performed to match the average reservoir pressure, and produced water cut. The final match involves the following changes: -

1. Modifying the following properties of the reservoir:

a) Changing the values of water, oil and formation compressibility as shown in table 2 but these changes were limited in the case of oil as it considered as a measured PVT property.

Table (2) The Values of Compressibility Before and After History Match

\begin{tabular}{|l|r|l|l|}
\hline & Actual value & & Value for history match \\
\hline Co & 0.00012400 & $1 /(\mathrm{kg} / \mathrm{cm} 2)$ & $0.000151 /(\mathrm{kg} / \mathrm{cm} 2)$ \\
\hline Cw & 0.00004400 & $1 /(\mathrm{kg} / \mathrm{cm} 2)$ & $0.0000981 /(\mathrm{kg} / \mathrm{cm} 2)$ \\
\hline Cf & 0.00002000 & $1 /(\mathrm{kg} / \mathrm{cm} 2)$ & $0.0000351 /(\mathrm{kg} / \mathrm{cm} 2)$ \\
\hline
\end{tabular}

b) Manipulating with the value of water viscosity (as no measured value is available) in order to obtain the most accurate produced water cut history. The final water viscosity value is $(0.6 \mathrm{cp})$.

c) Increase the permeability in the $x$ and $\mathrm{y}$ directions for the first two layers.

d) Multiply the transmissibility of the reservoir in the $x$ and $y$ directions by 0.5 , and in the $\mathrm{Z}$ direction by 0.7 . However for the

last three layers, which are water bearing, the transmissibility was multiplied by 0.01 for all directions. 
2. Modifying the aquifer properties.

As there is no any data about the aquifer so the modifications on the aquifer properties and features were made within reasonable values. Also many options were tested by editing the aquifer properties several times in order to reach to the best history match. The aquifer properties are given in table (3).

Table (3) Aquifer Properties

\begin{tabular}{|l|l|}
\hline \multicolumn{2}{|l|}{ Aquifer Properties } \\
\hline Location & bottom \\
\hline Thickness, m & 200 \\
\hline Porosity, fraction & 0.18 \\
\hline Permeability, md & 30 \\
\hline Radius, m & 100 \\
\hline R-ratio & 30 \\
\hline Modeling method & Fetkovitch \\
\hline
\end{tabular}

3. As the accurate date when the lower perforation interval was plugged is not available, so this interval was ignored to avoid unreasonable high water production as this interval lies very close to the OWC. The only perforation interval that was taken into consideration is the upper one $(3826-3838 m)$. 


\subsubsection{Pressure Matching Results}

The pressure history match results are shown in figure 5 .

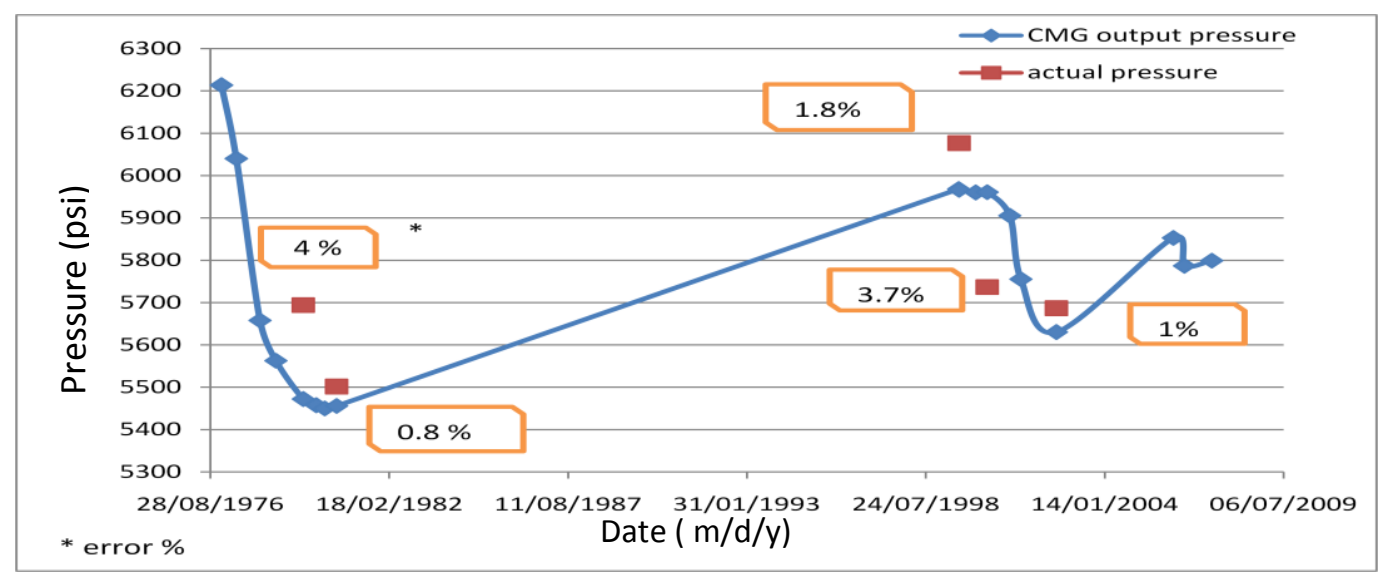

Fig . (5) The Values of Calculated and Measured Pressure verses Time

It could be noticed from the figure that the least error percentages are in the peaks of the pressure curve which represent the most important points as they show the trend of the pressure curve. The first and the third points with $4 \%$ and $3.7 \%$ error percentages respectively could be considered as an odd points because if the production history is checked it could be noticed that there is no production in July 2000 (see figure 6); while the pressure declined sharply in the measured data ${ }^{(8)}$ and that will lead to a conclusion that either there is an interference with other wells or some error is introduced in the measured values. The interference is excluded because all the adjacent wells are checked and they also have no production at this date. 


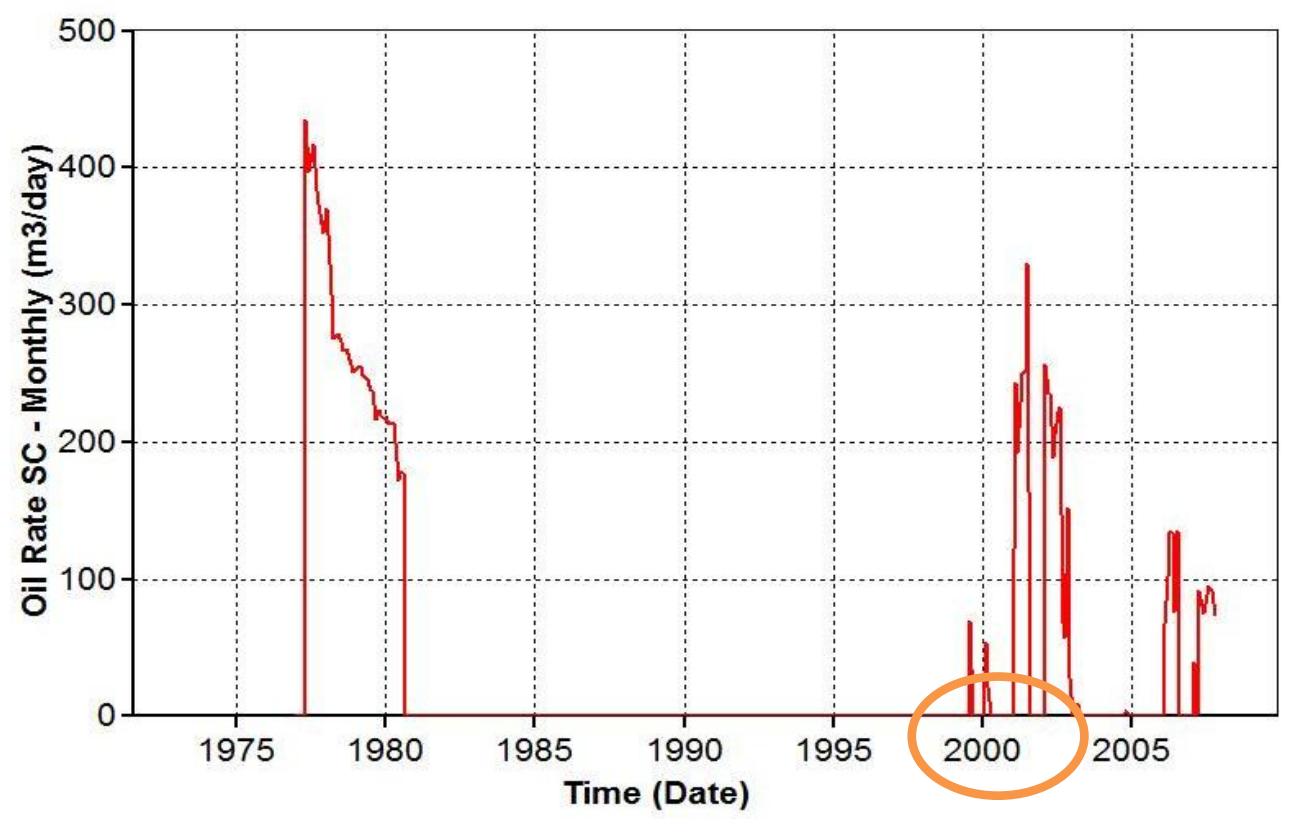

Fig .(6) Monthly Oil Rate versus Time

\subsubsection{Produced Water Cut Matching}

Produced Water Cut Matching Is Illustrated In Figure 7.

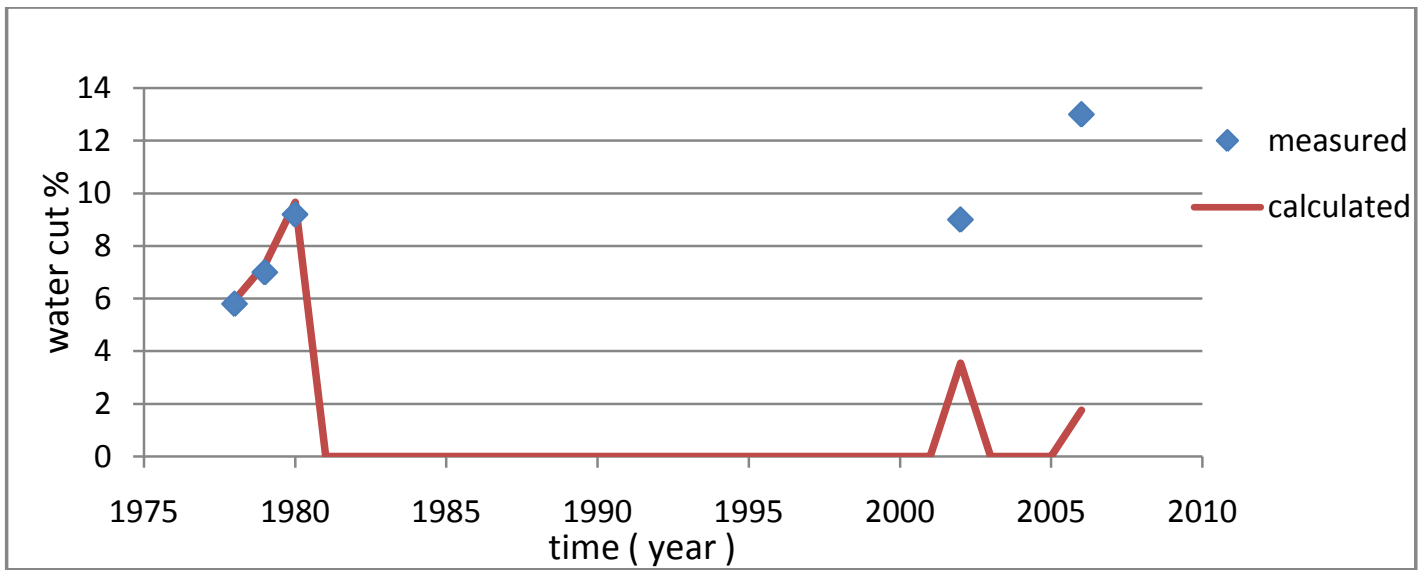

Fig .(7) The Calculated And Measured Water Cut Values Versus Time

The best match in the produced water cut values was in the period before the date of stopping the production (1980). After that both measured and calculated water cut are less than $15 \%$. 


\subsection{Water Saturation Distribution}

By noticing the water

saturation distribution around the wellbore through the history of the well, one can have an idea about the reason of water production from BU-3. It could be noticed from figures $8 \mathrm{a}$ to $8 \mathrm{e}$ that there is water coning in $\mathrm{Bu}-3$. These figures represent different production periods. The upper two layers represent the perforation interval. From figures $8 \mathrm{a}, 8 \mathrm{~b}$, and $8 \mathrm{c}$ it could be noticed how the water saturation is increased in the blocks above the OWC especially near the wellbore, but after the production was stopped the saturation is decreased and the water is settled down in one level (see figure 8d) but it increased back as the production resumed as in figure $8 \mathrm{e}$. 

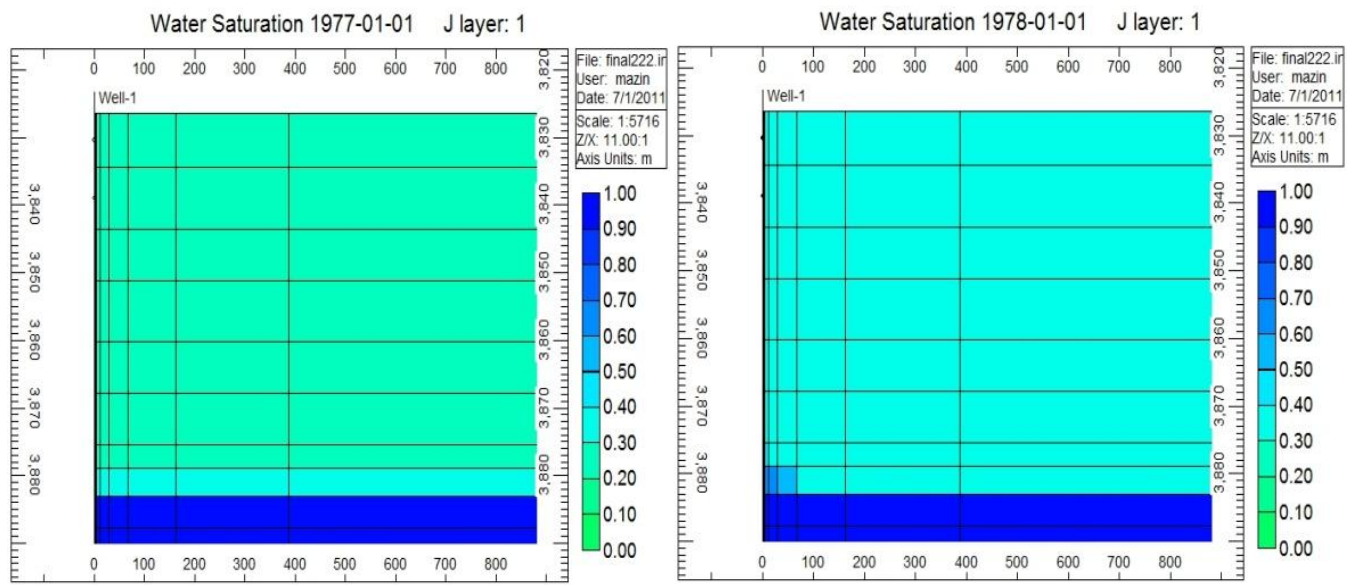

Fig. (8a) Water Saturation Distribution 1977 (Initial state)

Fig. (8b) Water Saturation Distribution

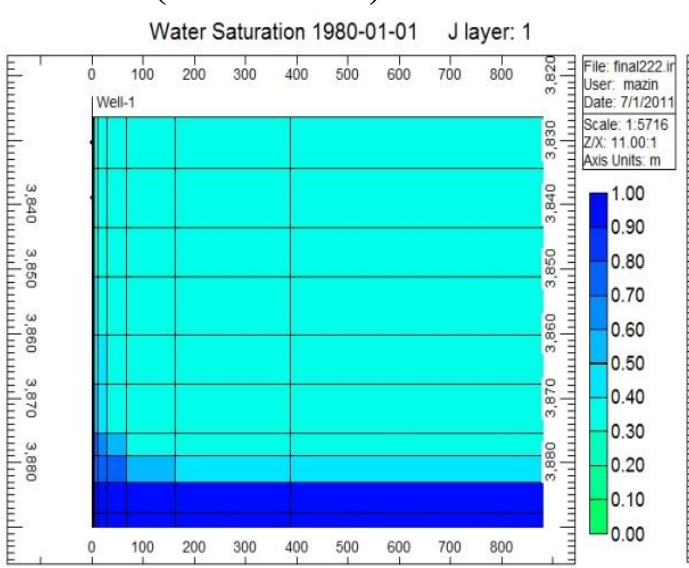
1978 (After production)

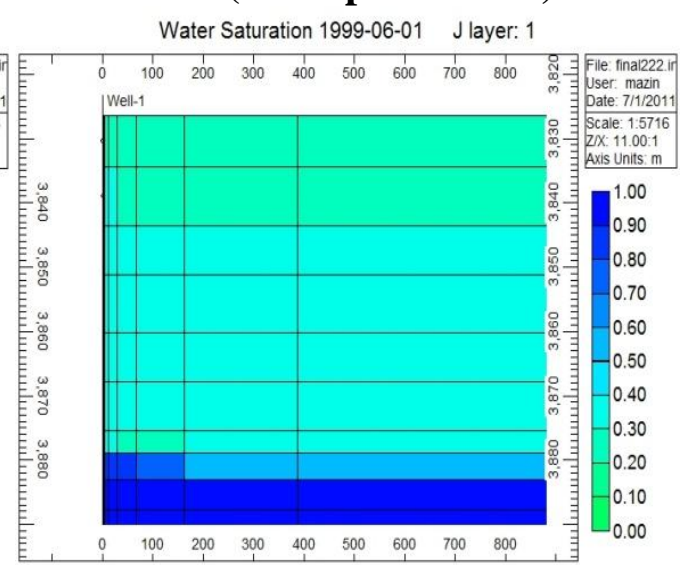

Fig. (8c) Water Saturation Distribution Fig. (8d) Water Saturation Distribution 1980(Continue in Production) 1999(After stopping production)
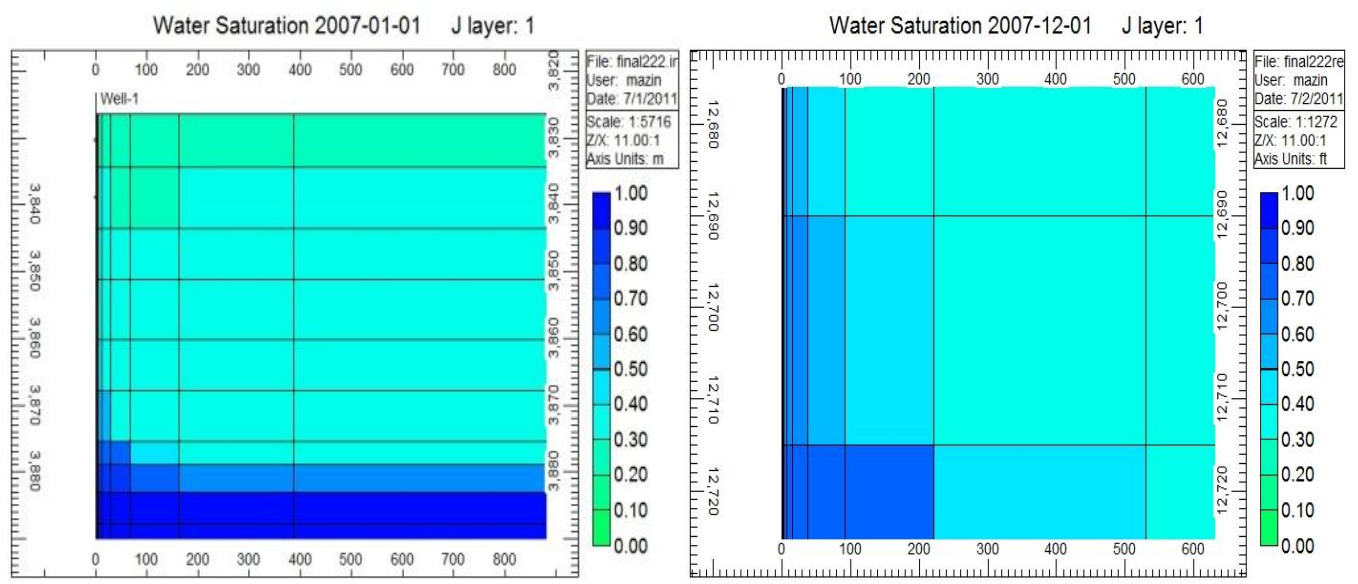

Fig. (8e) Water Saturation Distribution Fig. (8f) Water Saturation Distribution 2007 (The Production is Resumed) 2007 (Zoom view) 


\subsection{Future Prediction}

\subsection{1. $\quad$ Base Case}

In this case the well is opened for production after 2007 for 10 years at a rate of $90 \mathrm{~m}^{3} /$ day $(565$ bbl/day) which is the last production rate. The results for pressure and water cut are shown in figures 9 and 10. It could be noticed that the reservoir pressure is above
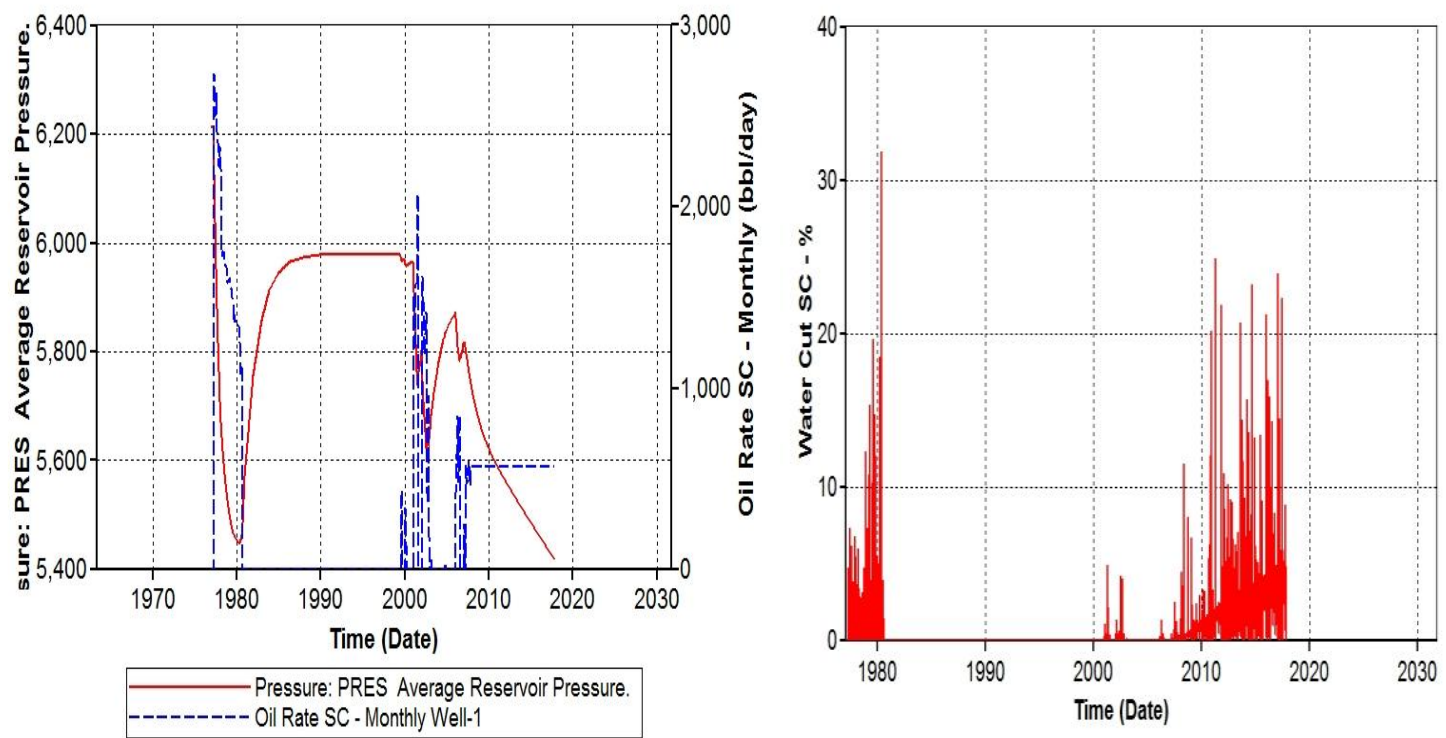

Fig .(9) Pressure and Oil Rate (Base Case
5400 psi which is away from the bubble point pressure of 2400 psi. Also the water cut which exceeds $20 \%$ is considered acceptable if we assume that the capacity of the surface facilities in handling the produced water is up to $30 \%$ water cut.

\subsubsection{Case Two: Double Production Rate}

In case two the production rate is doubled to $180 \mathrm{~m}^{3} /$ day $(1130 \mathrm{bbl})$.

In this case the produced water cut reached to a higher value of about $30 \%$ (see figures 11 and 12). 


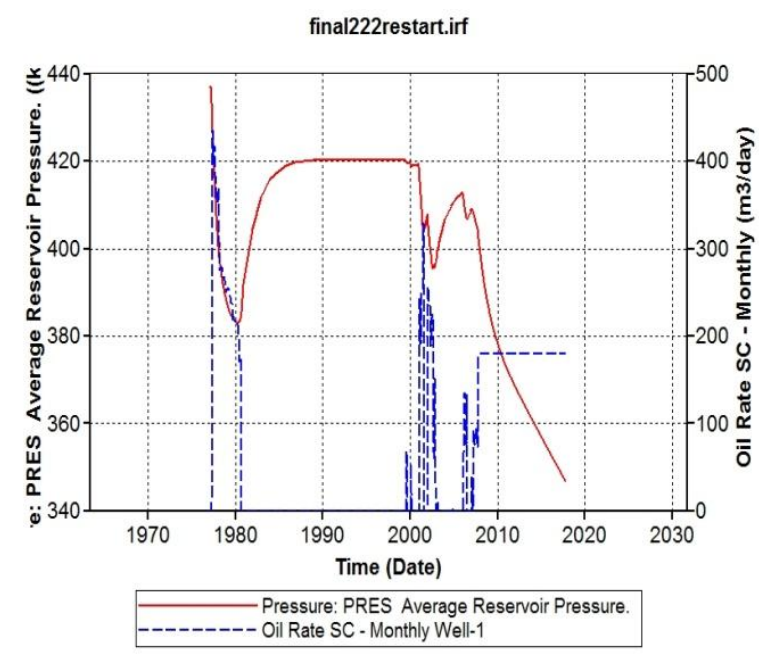

Fig. (11) Pressure and Oil Rate $\left(2^{\text {nd }}\right.$ Case $)$

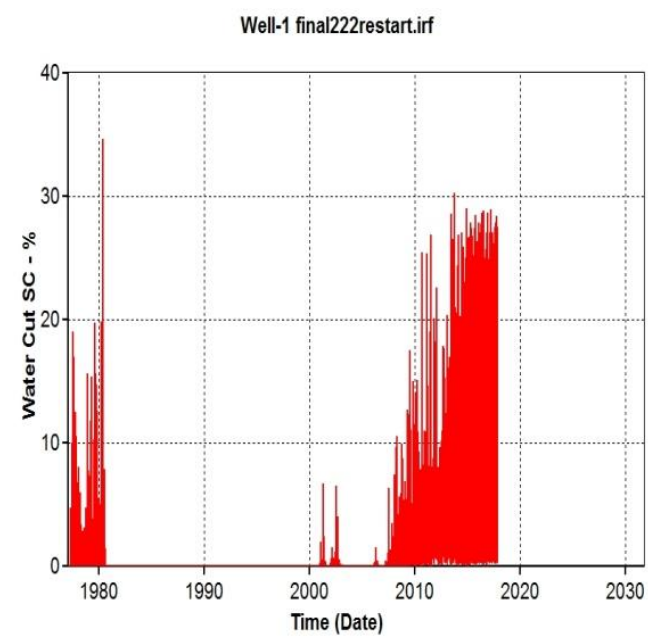

Fig (12). Water Cut $\left(2^{\text {nd }}\right.$ Case $)$

\section{Conclusions}

1. A single well model has been constructed to inspect the probability of water coning in $\mathrm{Bu}$ -

3. The model consists of 10 radial grids and 12 vertical layers. Fitkovitch method gives good response to match the aquifer in Buzurkan field.

2. It is believed that the second perforation interval was due to technical mistake so it's plugged directly after production as it was near the OWC.

3. There is water coning in BU-3 but the production is not so much affected because the active perforation interval is much higher than the OWC.

4. There is no water production problem even if we doubled the oil production in the next ten years.

5. BU-3 will be active for the next ten years with no significant pressure drop.

6. Single well model is considered as a very effective tool in the simulation studies as it needs less time to build in comparison with the entire field model and gives a comprehensive view about the overall reservoir. 
Sw : Water saturation, fraction

\section{8. $\underline{\text { Recommendations }}$}

$\Phi$ : Porosity, fraction

1. To have a better understanding about the aquifer features and performance more wells should be studied by using single well model.

2. This study could be coupled with an entire field zonation study to predict the optimum perforation intervals for the new wells in Buzurkan field.

\section{$\underline{\text { Nomenclature }}$}

Bg : Gas formation volume factor, $\mathrm{ft}^{3} / \mathrm{SCF}$

Bo : Oil formation volume factor, $\mathrm{bbl} / \mathrm{STB}$

Cf : Formation isothermal

compressibility, $\mathrm{psi}^{-1}$

Co : Oil isothermal

compressibility, $\mathrm{psi}^{-1}$

Cw : Water isothermal

compressibility, $\mathrm{psi}^{-1}$

Rs : Solution gas oil ratio $\mathrm{SCF} /$

STB 


\section{$\underline{\text { References }}$}

1. J.A. Holms and D.A. Edwards: (2010) "A Unified Wellbore Model for Reservoir Simulation,” SPE 134928, September.

2. Leonard F. Koederitz: (2004)“Lecture Notes on Applied Reservoir Simulation,".

3. Mazin H. Alattar :( 2011) “IRM/Final Report, “.

4. CPI , (1971), report for Bu-3, Ministry of Oil / Directory of Reservoirs' and Fields' Development.

5. Special Core Analysis of Bu-3, (1971) Ministry of Oil / Directory of Reservoirs' and Fields' Development.

6. PVT Analysis Report for Bu-5, (1976) Petroleum Research Institute.

7. Production Information for Buzurkan Field.

8. Buzurkan Field / Pressure Information. 